\title{
MRI image sequencing of calcified myocardial masses: liquefaction necrosis of mitral annular calcification (LNMAC)
}

\author{
David A Collins ${ }^{1 *}$, Melissa King-Strunk', Wojciech Mazur ${ }^{1}$, Amy Tipton², Sanjay S Srivatsa ${ }^{3}$ \\ From 2011 SCMR/Euro CMR Joint Scientific Sessions \\ Nice, France. 3-6 February 2011
}

\section{Introduction}

LNMAC presents as a cardiac mass with liquefied necrotic core and a thick inflammatory/fibrotic/calcified capsule peripherally.

\section{Purpose}

To characterize the diagnostic MRI sequences most useful in diagnosis of calcified myocardial masses.

\section{Methods}

CMRI imaging utilized a dedicated 8 cardiac coil system, the Siemens Avanto ${ }^{\mathrm{m}}$ 1.5Tesla MR scanner and gadolinium contrast. HASTE sequence (myocardial morphology), inversion recovery, Turbo FLASH and phase sensitive inversion recovery and True FISP sequences were utilized.

\section{Results}

The imaging characteristics are summarized in Table 1.

\section{Conclusions}

LNMAC histopathology reveals a necrotic core (amorphous eosinophilic material) and surrounding inflammatory rim (macrophage and lymphocytic infiltration) with zonal calcification. By MRI this zone of cellular inflammation and edema manifests as the zone of peripheral hyperenhancement on the PSIR, HASTE, and IR TURBOFLASH sequences. Most benign or malignant cardiac tumors show high T2 weighted imaging intensity, and are myocardial isointense on T1 weighted imaging before contrast administration. In contrast, the hypointense central zone of liquefactive necrosis seen on T1 and T2 weighted sequences,

Table 1 MRI Imaging Characteristics of LNMAC

\begin{tabular}{|c|c|c|}
\hline MRI SEQUENCE USED TO ASSESS LNMAC & INTERIOR CHARACTERISTIC OF MASS BY MRI & PERIPHERAL RING ENHANCEMENT \\
\hline $\begin{array}{l}\text { PHASE SENSITIVE/MAGNITUDE RECONSTRUCTION INVERSION } \\
\text { RECOVERY (PSIR) WITH MYOCARDIAL NULLING }\end{array}$ & $\begin{array}{l}\text { HYPOINTENSE } \neq \\
\text { łsignal intensity of central part of mass } \\
\text { compared with surrounding myocardium }\end{array}$ & $\begin{array}{l}+++ \text { (marked PERIPHERAL LATE } \\
\text { GADOLINIUM ENHANCEMENT) }\end{array}$ \\
\hline HASTE (T2 WEIGHTED SINGLE SHOT FSE) & $\begin{array}{l}\text { HYPOINTENSEF WITH HETEROGENEOUS } \\
\text { INTERIOR COMPONENTS }\end{array}$ & $\begin{array}{l}+++(\text { marked PERIPHERAL LATE } \\
\text { GADOLINIUM ENHANCEMENT) }\end{array}$ \\
\hline $\begin{array}{l}\text { IR TURBOFLASH (ULTRA FAST GRADIENT LOW ANGLE } \\
\text { SHOT T1 WEIGHTED) }\end{array}$ & $\begin{array}{l}\text { HYPOINTENSE } \neq \text { WITH HETEROGENEOUS } \\
\text { INTERIOR COMPONENTS }\end{array}$ & $\begin{array}{l}+++(\text { marked PERIPHERAL LATE } \\
\text { GADOLINIUM ENHANCEMENT) }\end{array}$ \\
\hline GRE (SPOILED GRADIENT ECHO) & $\begin{array}{l}\text { HYPERINTENSE CENTER AND HYPOINTENSE } \\
\text { RIM } \neq\end{array}$ & NONE \\
\hline TRUE FISP (STEADY STATE GRE MIXED T1 AND T2 WEIGHTING) & HYPOINTENSE $\neq$ & NONE \\
\hline $\begin{array}{l}\text { INVERSION RECOVERY TRUE FISP (SINGLE SHOT NON-BREATH } \\
\text { HOLD TECHNIQUE }\end{array}$ & HYPOINTENSEF & ++ \\
\hline STIR (SHORT TAU IR OR TRIPLE INVERSION RECOVERY) & HYPOINTENSE $\neq$ & ++ \\
\hline T2 TURBO SPIN (DARK BLOOD) ECHO (TSE) & HYPOINTENSE $\neq$ & ++ \\
\hline $\begin{array}{l}\text { T1 TURBO SPIN ECHO FAT SAT POST CONTRAST DARK BLOOD } \\
\text { (TSE) }\end{array}$ & $\begin{array}{l}\text { HYPOINTENSE } \neq \text { WITH HETEROGENEOUS } \\
\text { INTERIOR COMPONENTS }\end{array}$ & NONE \\
\hline
\end{tabular}

${ }^{1}$ The Christ Hospital, Cincinnati, OH, USA

Full list of author information is available at the end of the article

\section{Biomed Central}

(C) 2011 Collins et al; licensee BioMed Central Ltd. This is an open access article distributed under the terms of the Creative Commons Attribution License (http://creativecommons.org/licenses/by/2.0), which permits unrestricted use, distribution, and reproduction in any medium, provided the original work is properly cited. 


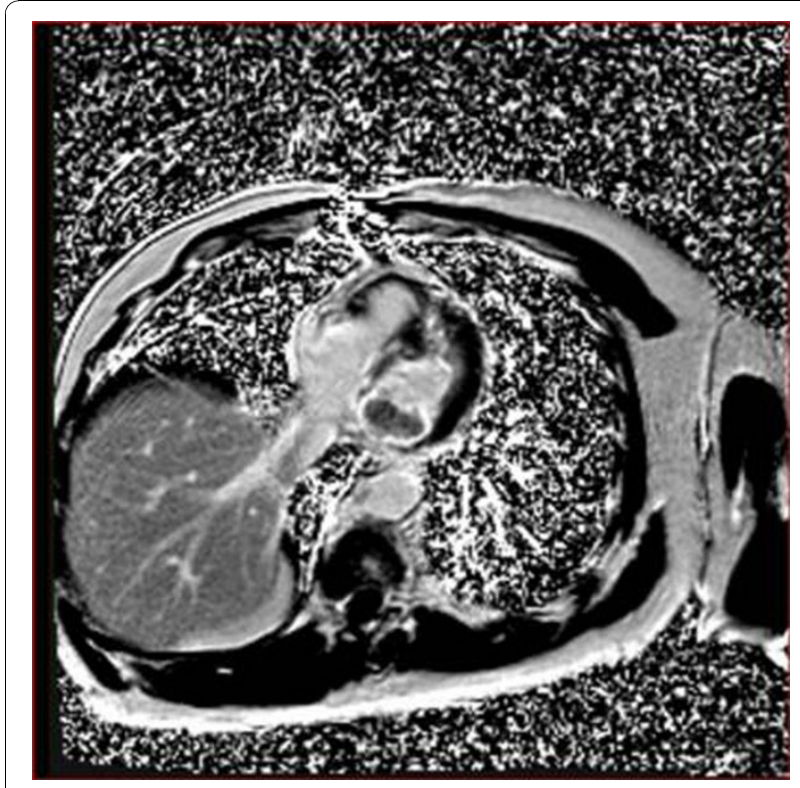

Figure 1 Horizontal long axis 4 chamber view: PSIR.

and the surrounding bright ring like zone of hyperintensity seen with both T2 weighted HASTE and phase sensitive (PSIR)inversion recovery sequences, serves along with its typical location and calcified content to distinguish it from other cardiac tumors. Shortening the inversion time of the inversion recovery sequence (STIR), enhances sensitivity to

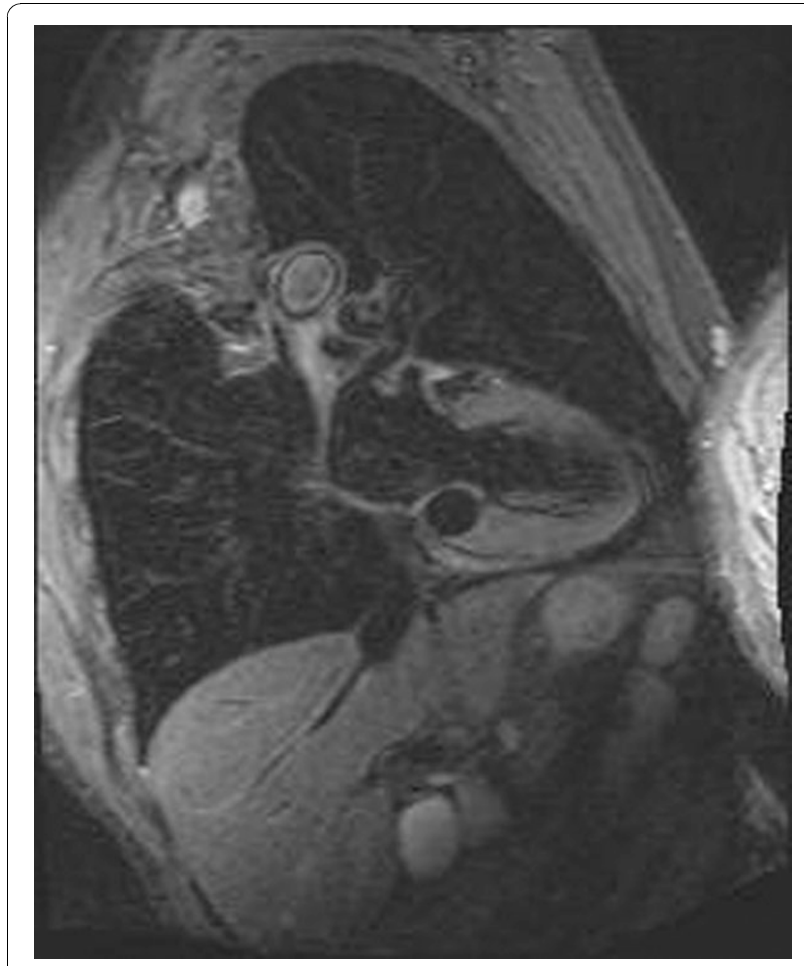

Figure 2 STIR imaging using a short inversion time to suppress fat.

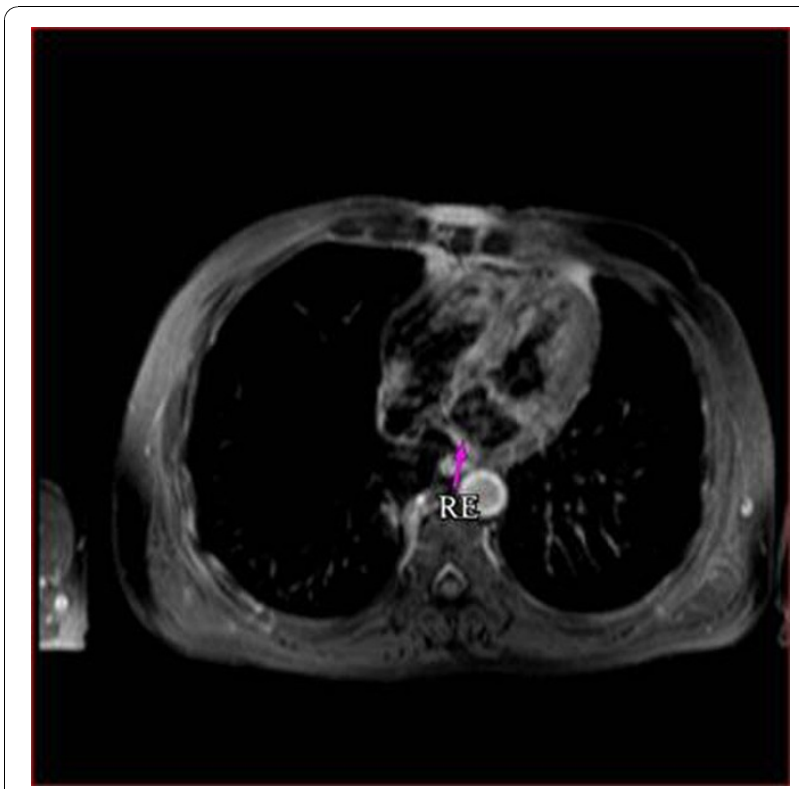

Figure 3 T1 weighted, post contrast, dark blood, fat saturated, turbospin echo.

certain types of pathology by making the effects of prolonged T1 and T2 on signal intensity additive and nulling fat signal. Both tumor and inflammatory pathologies may therefore be separated in terms of contrast, from fat and muscle as in this case. The T2-weighted edema imaging using a breath-hold single-shot sequence with half-Fourier imaging (HASTE) maps the ring like area of pronounced inflammation and associated edema, surrounding the central area of liquefactive necrosis, which is comparatively

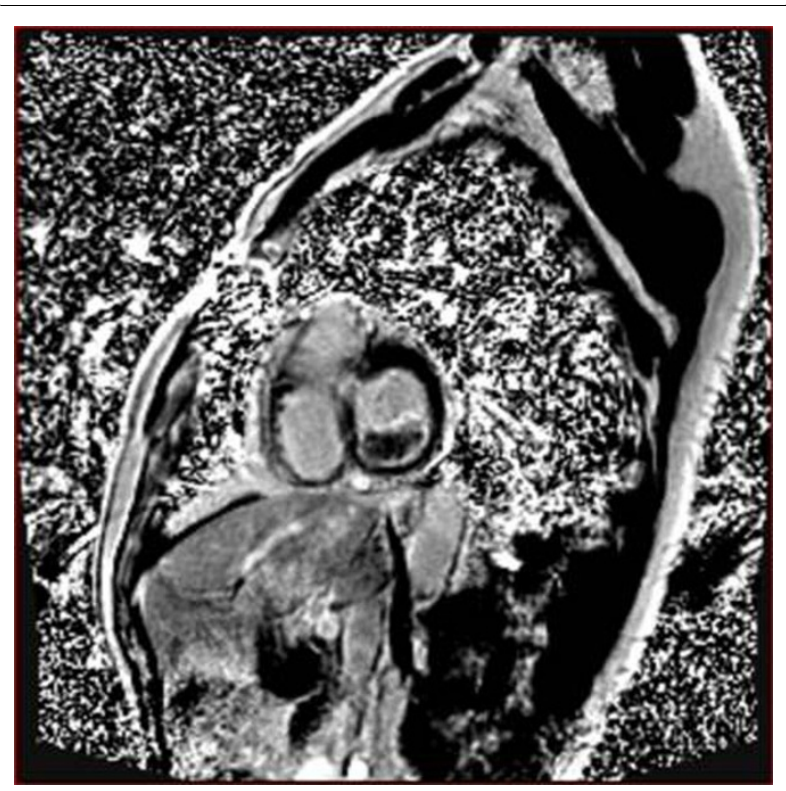

Figure 4 PSIR short axis cross-section at mitral valve annulus. 


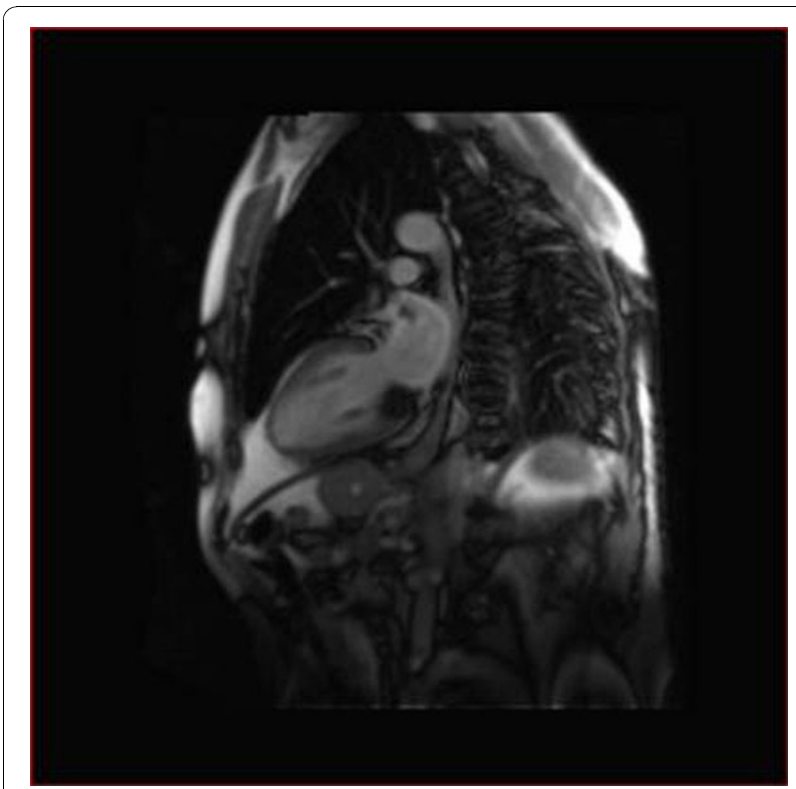

Figure 52 chamber $\mathrm{T} 1$ weighted image demonstrating hypointense lesion compared with surrounding myocardium.

less intense compared with the outer ring zone. Likewise, a breath hold inversion recovery segmented turbo fast lowangle (IR turboFLASH) sequence for T1-weighted postcontrast imaging, or T2-weighted short TI inversion-recovery precontrast imaging (STIR) both yield a well defined ring like area of signal enhancement around a hypointense core. These MRI sequence characteristics are diagnostic of LNMAC. Figures 1, 2, 3, 4, 5, 6, 7.

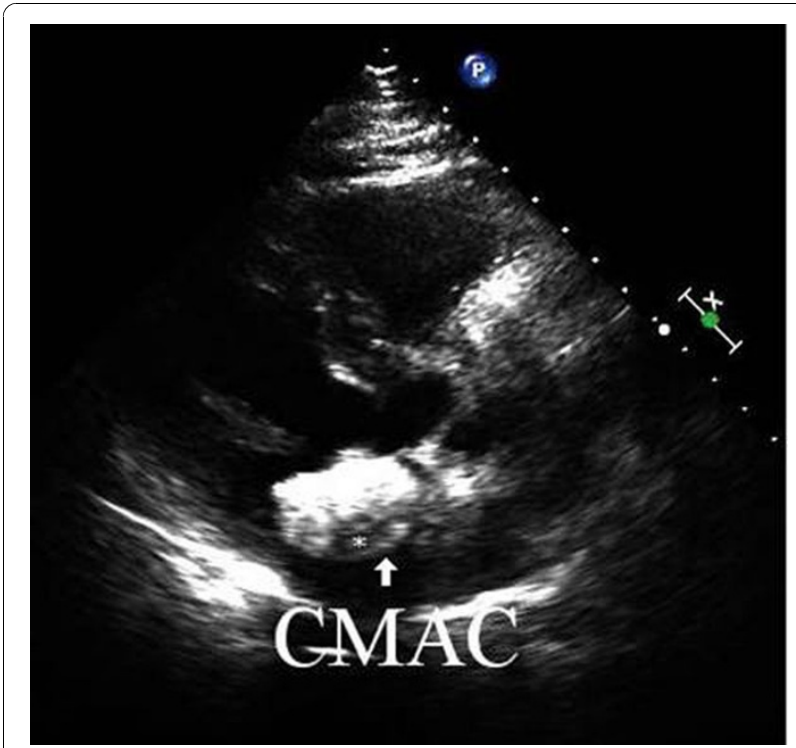

Figure 6 Transthoracic echocardiography two dimensional parasternal long axis.

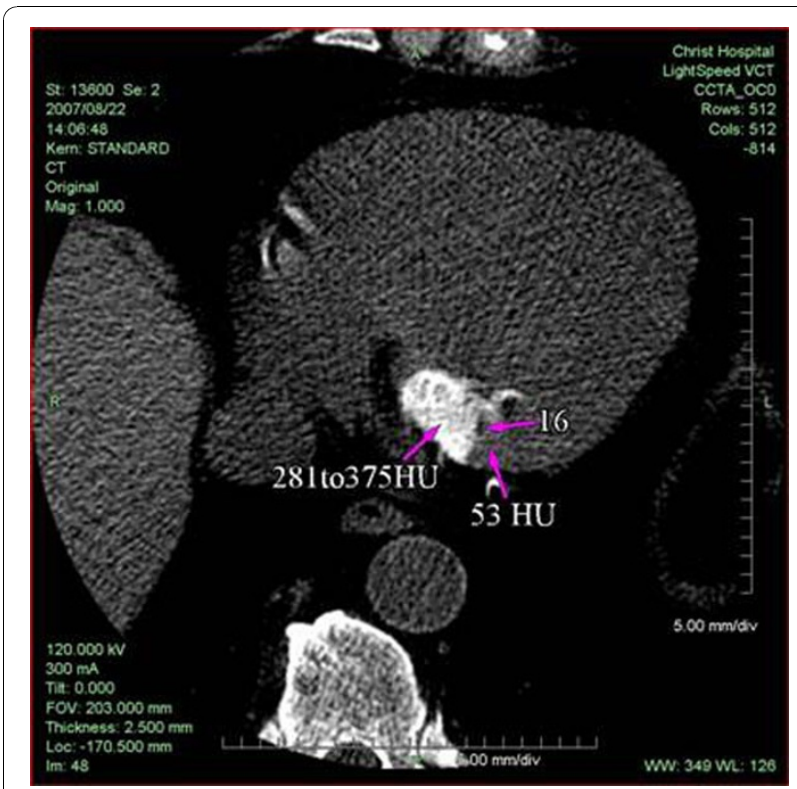

Figure 7 High resolution thin section CT axial view.

\section{Author details}

${ }^{1}$ The Christ Hospital, Cincinnati, OH, USA. ${ }^{2}$ Cincinnati Childrens Hospital Medical Center, Cincinnati, OH, USA. ${ }^{3}$ Marion Medical Center, Santa Maria, CA, USA.

Published: 2 February 2011

doi:10.1186/1532-429X-13-S1-P353

Cite this article as: Collins et al:: MRI image sequencing of calcified myocardial masses: liquefaction necrosis of mitral annular calcification (LNMAC). Journal of Cardiovascular Magnetic Resonance 2011 13(Suppl 1): P353.

\section{Submit your next manuscript to BioMed Central} and take full advantage of:

- Convenient online submission

- Thorough peer review

- No space constraints or color figure charges

- Immediate publication on acceptance

- Inclusion in PubMed, CAS, Scopus and Google Scholar

- Research which is freely available for redistribution 